EESTI NSV TEADUSTE AKADEEMIA TOIMETISED. XV KÖIDE FUOSIKA-MATEMAATIKA- JA TEHNIKATEADUSTE SEERIA, 1966, NR. 1

ИЗВЕСТИЯ АКАДЕМИИ НАУК ЭСТОНСКОИ ССР. ТОМ ХV

СЕРИЯ ФИЗИКО-МАТЕМАТИЧЕСКИХ И ТЕХНИЧЕСКИХ НАУК. 1966, № 1

V. SINIVEE, E. LIPPMA.A

\title{
WEAK PERTURBING RADIO-FREQUENCY FIELD EFFECTS IN NUCLEAR MAGNETIC DOUBLE RESONANCE. III
}

In the first paper of this series [1], hereafter referred to as I, a density matrix equation for spectral lines in NMDR spectra of nondegenerate spin systems, interacting with weak perturbing $r f$ fields, has been given. An analysis of this equation for the special case of spectral lines without a common energy level with the perturbed line was presented in the second paper $\left[{ }^{2}\right]$, referred to below as II. In this paper an analysis of line shapes and intensities for lines with a common energy level with the perturbed line is given. The same notation and convention for signs and indices as in I has been used. Since frequency-swept spectra are much simpler to interpret, only this case has been considered.

\section{The line-shape equation for weak perturbing fields}

In order to rend the "tickling" equation (I 64) more amenable for interpretation, let us introduce new variables

$$
Z=x_{1} \mp \eta ; \quad \eta=x_{2} ; \quad f=\frac{V_{t d^{\prime}}}{\lambda_{t d^{\prime}}},
$$

so that the equation (I 64) takes the form

$$
f(Z, \eta)=\left(1 \mp \tau_{1} S\right) f_{1}(Z, \eta) \mp \frac{S}{\tau_{2}} f_{2}(Z, \eta)
$$

where

$$
\begin{aligned}
& f_{1}(Z, \eta)=\frac{p_{1}\left(1+Z^{2}\right)}{p_{1}^{2}+v_{1}^{2} q_{1}^{2}} \\
& f_{2}(Z, \eta)=\frac{p_{2} \pm v_{2} \eta q_{2}}{p_{2}^{2}+q_{2}^{2}}
\end{aligned}
$$

and

$$
\begin{aligned}
& p_{1}=1+v_{1} h^{2}+Z^{2} \\
& q_{1}=Z^{3} \pm \eta Z^{2}+\left(1-h^{2}\right) Z \pm \eta \\
& p_{2}=1+v_{1} h^{2}-v_{1} Z(Z \pm \eta) \\
& q_{2}=Z+v_{1}(Z \pm \eta)
\end{aligned}
$$


The equation (2) with the new variables is suitable for the line intensity calculations, while in order to find the line shapes a transformation to a simpler form is indicated.

Noting that the denominator of the fraction in the right-hand side of (3) may be presented in the form

$$
B_{1}(Z)=\left(v_{1} q_{1}-i p_{1}\right)\left(v_{1} q_{1}+i p_{1}\right)
$$

we find the roots of $B_{1}(Z)$ from the equations

where

$$
\begin{aligned}
& Z^{3}-a Z^{2}+b Z-c=0, \\
& Z^{3}-\bar{a} Z^{2}+b Z-\bar{c}=0,
\end{aligned}
$$

If $Z_{1}, Z_{2}$ and $Z_{3}$ are solutions of the equation (10), then the complex conjugate quantities $\bar{Z}_{1}, \bar{Z}_{2}$ and $\bar{Z}_{3}$ are solutions of equation (11). It may be proved by insertion that $Z_{3}=-i$. Using this pair of solutions, we get from (9)

$$
B_{1}(Z)=v_{1}^{2}\left(1+Z^{2}\right)\left[Z^{2}-(a+i) Z+i c\right]\left[Z^{2}-(\bar{a}-i) Z-i \vec{c}\right] .
$$

It can be seen from (15) that the other roots of (9) are

where

$$
\begin{aligned}
& Z_{1}=\mp \frac{\eta}{2}+i \frac{v_{1}+1}{2 v_{1}}+\alpha, \\
& Z_{2}=\mp \frac{\eta}{2}+i \frac{v_{1}+1}{2 v_{1}}-\alpha,
\end{aligned}
$$

$$
\alpha=\sqrt{h^{2}+\left(\frac{\eta}{2}\right)^{2}-\left(\frac{v_{1}-1}{2 v_{1}}\right)^{2} \pm i \eta \frac{v_{1}-1}{2 v_{1}}}
$$

and the roots $\alpha$ are chosen so that $\operatorname{Im} \alpha>0$.

Inserting (12), (13) and (14) into (15) one obtains a new expression for $B_{1}(Z)$

$$
B_{1}(Z)=v_{1}^{2}\left(1+Z^{2}\right) D(Z)
$$

where

$$
\begin{aligned}
D(Z)=Z^{4} \pm 2 \eta Z^{3}+ & {\left[\eta^{2}-2 h^{2}+\frac{v_{1}^{2}+1}{v_{1}^{2}}\right] Z^{2} \pm 2 \eta\left(1-h^{2}\right) Z+} \\
& +\left[\eta^{2}+\left(h^{2}+\frac{1}{v_{1}}\right)^{2}\right]
\end{aligned}
$$

5 ENSV TA Toimetised F-1 66. 
Now, the denominator in (4) equals $v_{1}^{2} D(Z)$, as can be proved by the use of (7) and (8). Consequently, we can write (2) as

$$
f(Z, \eta)=\frac{E(Z)}{v_{1}^{2} D(Z)},
$$

where

$$
\begin{aligned}
E(Z)= & {\left[1 \mp\left(\tau_{1}-\frac{v_{1}}{\tau_{2}}\right) S\right] Z^{2}+\frac{S}{\tau_{2}} \eta\left[v_{1}+v_{2}\left(v_{1}+1\right)\right] Z+} \\
& +\left[1 \mp\left(\tau_{1}+\frac{1}{\tau_{2}}\right) S\right]\left(1+v_{1} h^{2}\right) \mp \frac{S}{\tau_{2}} \eta v_{1} \gamma_{2} .
\end{aligned}
$$

\section{Calculation of the line shapes}

Equation (21) can be used to calculate NMDR line shapes if the perturbing fields are weak and acting selectively upon some transitions. A homogeneous static magnetic field is assumed thus far. In case of exact resonance of the perturbing field $\eta=0$ the equation (21) takes a simple form

$$
f(Z, 0)=\frac{m_{1} y+m_{2}}{v_{1}^{2}\left(y^{2}-n_{1} y+n_{2}\right)},
$$

where

$$
\begin{aligned}
y & =Z^{2} \\
m_{1} & =1 \mp\left(\tau_{1}-\frac{v_{1}}{\tau_{2}}\right) S \\
m_{2} & =\left(1+v_{1} h^{2}\right)\left[1 \mp\left(\tau_{1}+\frac{1}{\tau_{2}}\right) S\right] \\
n_{1} & =2 h^{2}-\frac{v_{1}^{2}+1}{v_{1}^{2}} \\
n_{2} & =\left(h^{2}+\frac{1}{v_{1}}\right)^{2} \\
S & =\frac{2 h^{2} v_{2} \tau_{2}}{1+2 h^{2} v_{2} \tau_{2}} .
\end{aligned}
$$

It can be seen from (23) and (24) that

and

$$
f(-Z)=f(Z)
$$

$$
f(Z, 0) \rightarrow 0 \text {, if } Z \rightarrow \pm \infty \text {. }
$$

To characterize the line-shapes more completely, let us find the extremums, of $f(Z, 0)$, which can be found from the following equations:

$$
\begin{gathered}
Z=0, \\
\frac{\partial f}{\partial y}=0 .
\end{gathered}
$$


Inserting (23) into (33) one obtains a quadratic equation for $y=Z^{2}$

$$
y^{2}+2 \frac{m_{2}}{m_{1}} y-\left(n_{2}+n_{1} \frac{m_{2}}{m_{1}}\right)=0,
$$

with the possible roots

where

$$
\begin{aligned}
& y_{1}=-k\left(1+v_{1} h^{2}\right)+\beta, \\
& y_{2}=-k\left(1+v_{1} h^{2}\right)-\beta,
\end{aligned}
$$

and

$$
k=\frac{1 \mp\left(\tau_{1}+\frac{1}{\tau_{2}}\right) s}{1 \mp\left(\tau_{1}-\frac{v_{1}}{\tau_{2}}\right) s} .
$$

Let us study the case $k>0$ first.

For weak $r f$ fields, so that $\quad \beta<k\left(1+v_{1} h^{2}\right)$

line splittings do not occur. The peak height in this case is given by

$$
f(0,0)=\frac{1 \mp\left(\tau_{1}+\frac{1}{\tau^{2}}\right) s}{1+v_{1} h^{2}} .
$$

In the $\Lambda=0$ case (regressive transition) the peak height decreases with increasing $r f$ field strength until the inequality (39) is reversed and line splitting results. In the $\Lambda=2$ case (progressive transition) there are two possibilities; either the peak height $f(0,0)$ increases at first with increasing $r f$ field strength and then begins to diminish with the occurrence of line splitting as soon as the inequality (39) no longer holds, or the peak height decreases monotonously. The second case obtains if an additional inequality holds

$$
2 v_{2} \tau_{2}\left(\tau_{1}+\frac{1}{\tau_{2}}\right) \leqslant v_{1} .
$$

The maximums of $f(Z, 0)$ for the case of line splittings can be found by inserting (35) into (24) and the corresponding peak height by inserting (35) into (23). With increasing $r f$ field strength parameter $h$, the peak heights tend to an asymptotic value

$$
f( \pm h, 0)=\frac{1 \mp \tau_{1}}{v_{1}+1} .
$$

The above formula (42) is a good approximation if

$$
\begin{gathered}
\gamma^{2} H_{2}^{2} T_{1} T_{2} \gg 1, \\
\gamma H_{2} \gg \frac{1}{T_{2}} .
\end{gathered}
$$

In these inequalities (43), (44) $T_{1}$ and $T_{2}$ denote quantities of the type $\left|T_{a b 1}\right|$ and $T_{g h 2}$. With these conditions the equation (35) leads to the simple result

$$
Z= \pm h \text {. }
$$


Note that in (45) and in the left-hand side of (42) the signs correspond to the halves of a symmetrically split line. The signs in the righthand side of (42) correspond to the $\Lambda=0 ; 2$ cases.

The equation (45) corresponds to the "tickling" equation of Freeman and Anderson [3], but the peak heights (42) still depend upon relaxation parameters, even in the case of saturation (43). Indeed, by inserting (I 57) and (I 58) into (1) and (45) we obtain equation (12) of ref. [ $\left.{ }^{3}\right]$ for exact resonance $\left(\omega_{2}-\omega_{r s}=0\right.$ in the notation of $\left.\left[^{3}\right]\right)$.
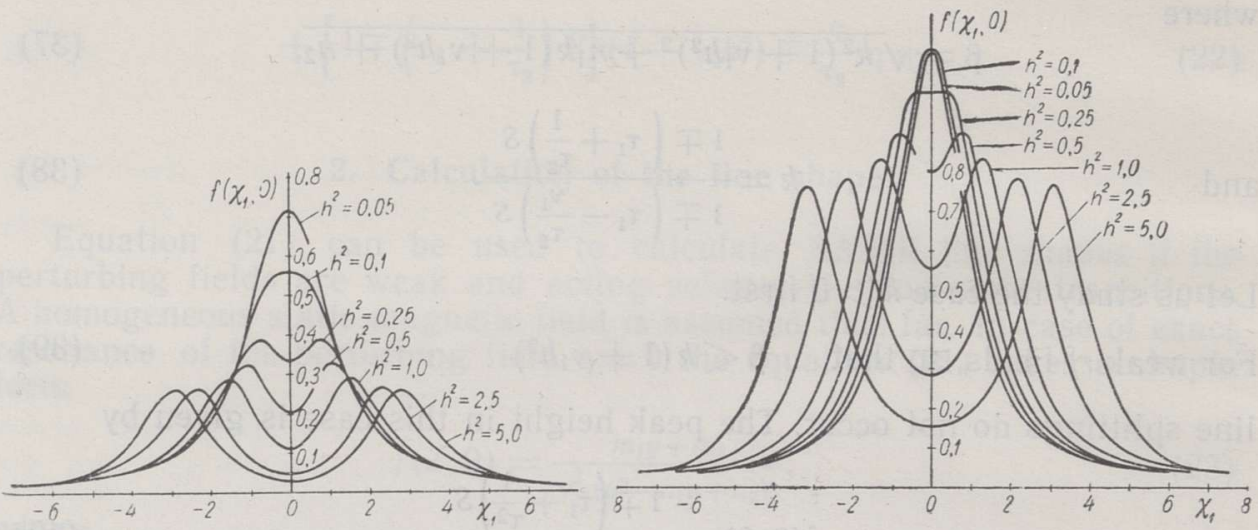

Fig 1. Calculated line shapes in case of homogeneous static magnetic field for various values of $r f$ field strength parameter $h . \tau_{1}=0,5 ; \tau_{2}=4 ; v_{1}=v_{2}=1 . \Lambda=0$ case on the left and $\Lambda=2$ case on the right.

Some rumerically calculated line shapes for various values of the $r f$ field strength parameter $h$ are given in fig. 1. The relaxation parameters have the following chosen values: $\tau_{1}=0,5, \tau_{2}=4, v_{1}=v_{2}=1$. The monoresonance peak height equals 1,0 .

The interesting case of $k<0$ is possible in case of a fairly strong $r f$ field if the following inequalities hold:

$$
\begin{array}{ll}
T_{c^{\prime} d^{\prime} 2}>T_{c^{\prime} d^{\prime} 1} & \text { if } \Lambda=0, \\
T_{c^{\prime} d^{\prime} 2}>T_{c^{\prime} d^{\prime} 1}+T_{c^{\prime} c 1} & \text { if } \Lambda=2 .
\end{array}
$$

The question whether these conditions are consistent with the equations (I 47) and real relaxation mechanisms, is outside the scope of this paper. Here we note only the line shapes that correspond to the $k<0$ case. In addition to the two maximums (35) we obtain in this case two symmetrically placed minimums (36), where the function $f(Z, 0)$ has a negative sign. In the $\Lambda=0$ case these minimums occur between the maximums (35), but in the $\Lambda=2$ case on the outside. The minimums are greatest at intermediate $r f$ field strengths. At $Z=0$ one obtains in the $\Lambda=0$ case a maximum with a negative absolute value, and a positive minimum in the $\Lambda=2$ case. Some line shapes for the $k<0$ case are presented in figs 4 and 5 .

In the important case of inhomogeneous static magnetic field the line shape is given by equation (I 73). Introducing dimensionless quantities

$$
\begin{aligned}
& x_{1}^{*}=\Delta \omega_{1}^{*} T_{r d^{\prime} 2}, \\
& x_{2}^{*}=\Delta \omega_{2}^{*} T_{r d^{\prime} 2},
\end{aligned}
$$




$$
\begin{aligned}
\xi^{*} & =\xi T_{r d^{\prime} 2}, \\
F\left(x_{1}^{*}, x_{2}^{*}\right) & =\frac{V_{t d^{\prime}}^{*}}{\lambda_{t d^{\prime}}}, \\
G\left(\xi^{*}\right) & =\frac{g(\xi)}{T_{r d^{\prime} 2}}
\end{aligned}
$$

the equation (I 73)

takes the form

$$
F\left(x_{1}^{*}, x_{2}^{*}\right)=\int_{-\infty}^{+\infty} f\left(x_{1}^{*}-\xi^{*}, x_{2}^{*}-\xi^{*}\right) G\left(\xi^{*}\right) d \xi^{*}
$$
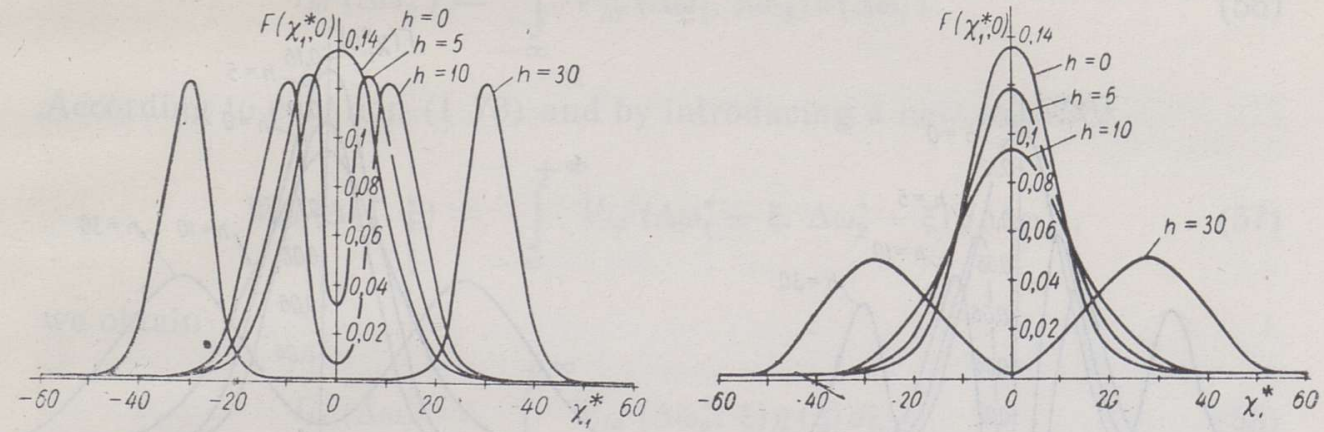

Fig. 2. Calculated line shapes in case of inhomogeneous static magnetic field for various values of $r$ field strength parameter $h . \tau_{1}=0 ; \tau_{2}=10 ; v_{1}=v_{2}=1 . \Lambda=0$ case on the left and $\Lambda=2$ case on the right.
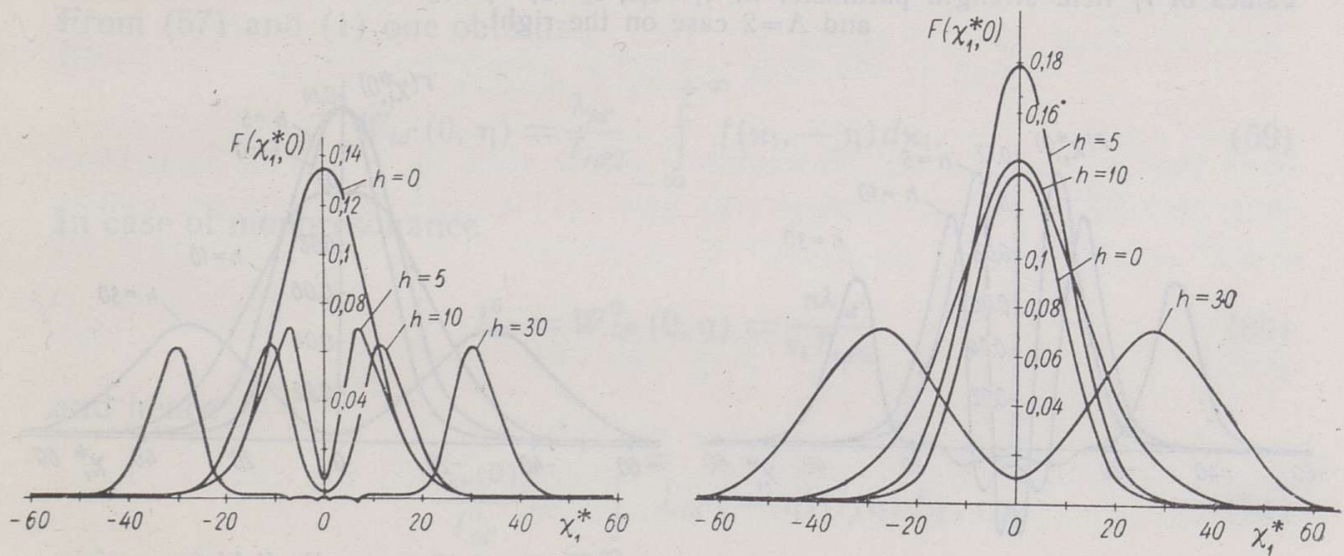

Fig. 3. Calculated line shapes in case of inhomogeneous static magnetic field for varions values of $r f$ field strength parameter $h$. $\tau_{1}=0,5 ; \tau_{2}=10 ; v_{1}=v_{2}=1 . \Lambda=0$ case on the left and $\Lambda=2$ case on the right.

Since the shape of a spectral line depends strongly upon small deviations from exact resonance and the shape function, the equation (23) may not give adequately exact results in case of real inhomogeneous static magnetic fields. To characterize to some extent the effect of magnetic field inhomogeneity, the more exact but complicated equation (53) has been used for numerical line shape calculations. A normalized Gauss shape function 
with

$$
G\left(\xi^{*}\right)=\tau^{*} \sqrt{\frac{\ln 2}{\pi}} \exp \left[-(\ln 2)\left(\tau^{*} \xi^{*}\right)^{2}\right]
$$

$$
\tau^{*}=\frac{T_{2}^{*}}{T_{r d^{\prime 2}}}=0,1
$$

and $\frac{1}{T_{2}^{*}}$ as half width have been used. As before, it has been chosen that $v_{1}=v_{2}=1$ and $x_{2}^{*}=0$, but a variety of values for the parameters $\tau_{1}, \tau_{2}$ and $h$ have been used.

Some representative shapes are set out in figs $2,3,4$ and 5 .
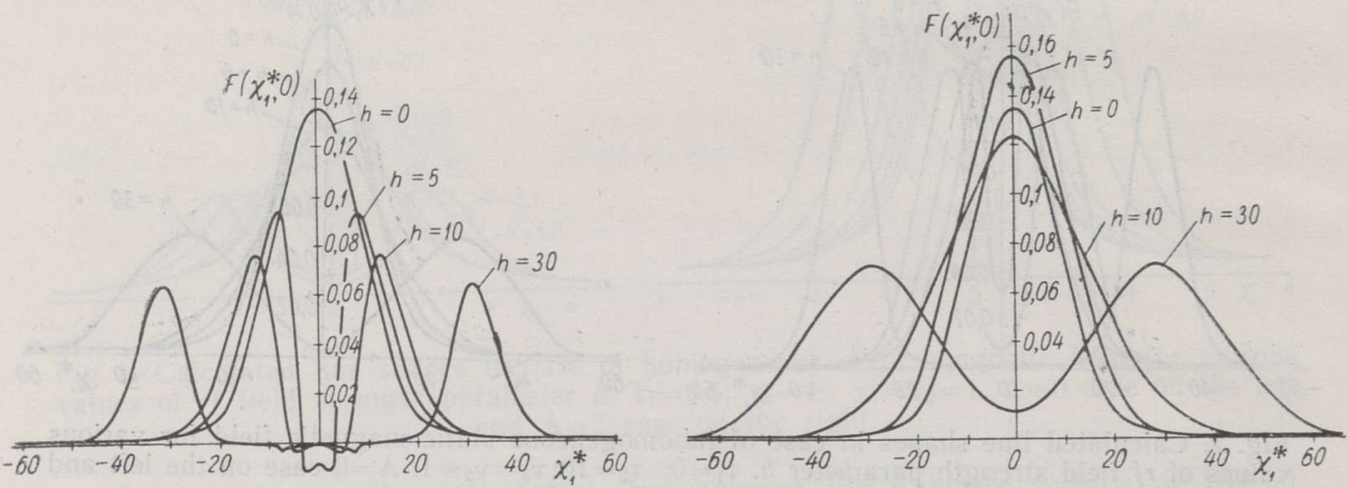

Fig. 4. Calculated line shapes in case of inhomogeneous static magnetic field for various values of $r f$ field strength parameter $h . \tau_{1}=0,5 ; \tau_{2}=2 ; v_{1}=v_{2}=1 . \Lambda=0$ case on the left and $\Lambda=2$ case on the right.
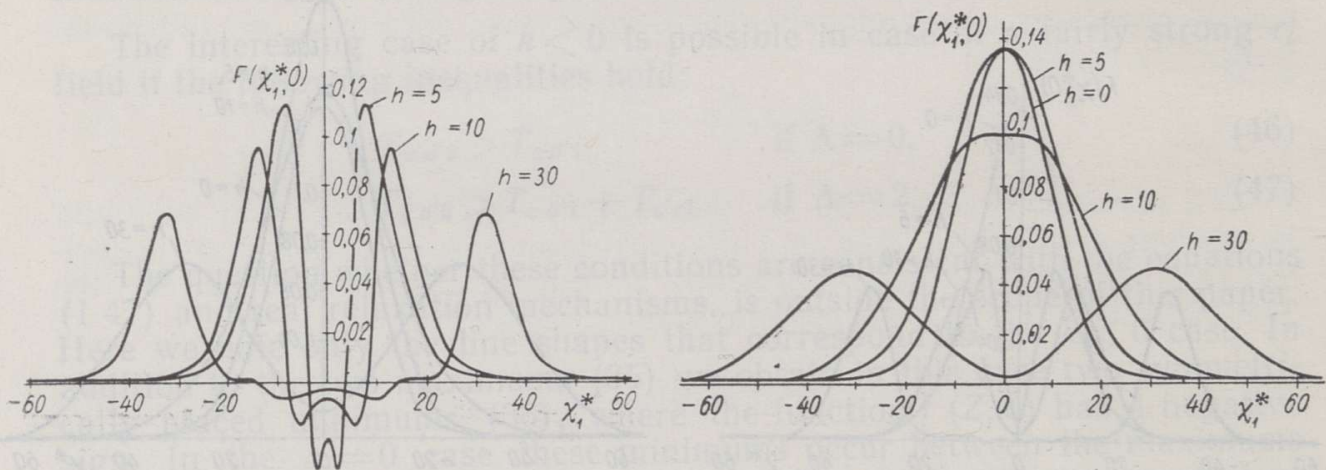

Fig. 5. Calculated line shapes in case of inhomogeneous static magnetic field for various values of $r f$ field strength parameter $h . \tau_{1}=0,5 ; \tau_{2}=1 ; v_{1}=v_{2}=1 . \Lambda=0$ case on the left and $\Lambda=2$ case on the right.

It can readily be seen that very weak $r f$ fields cause no splittings. The height of line center $F\left(x_{1}^{*}, 0\right)$ decreases with increasing $r f$ field strength in the $\Lambda=0$ case and increases in the $\Lambda=2$ case. Note that for the chosen relaxation parameters in figs 3,4 and 5 the inequality (41) does not hold. A sufficiently strong $r f$ field causes a line splitting in all cases. Unlike the case of line splitting in homogeneous magnetic field (fig. 1), a characteristic difference between $\Lambda=0$ and $\Lambda=2$ lines occurs, as described by 
Freeman and Anderson [3]. The split lines sharpen in the $\Lambda=0$ case and widen in the $\Lambda=2$ case, and in the $\Lambda=0$ case a splitting occurs at lower $r i$ field strengths.

Equation (45) is approximately correct for stronger $r f$ fields, and particulary so for $\Lambda=0$ lines with small $\tau_{1}$ and large $\tau_{2}$ values.

\section{Line intensities}

The intensity of a NMDR line in inhomogeneous magnetic field is given by

$$
I_{t d^{\prime}}\left(\Delta \omega_{2}^{*}\right)=\int_{-\infty}^{+\infty} V_{t d^{\prime}}^{*}\left(\Delta \omega_{1}^{*}, \Delta \omega_{2}^{*}\right) d\left(\Delta \omega_{1}^{*}\right) .
$$

According to equation (I 73) and by introducing a new quantity

$$
W_{t d^{\prime}}\left(\Delta \omega_{2}^{*}, \xi\right)=\int_{-\infty}^{+\infty} V_{t d^{\prime}}\left(\Delta \omega_{1}^{*}-\xi, \Delta \omega_{2}^{*}-\xi\right) d\left(\Delta \omega_{1}^{*}\right)
$$

we obtain

$$
I_{t d^{\prime}}\left(\Delta \omega_{2}^{*}\right)=\int_{-\infty}^{+\infty} W_{t d^{\prime}}\left(\Delta \omega_{2}^{*}, \xi\right) g(\xi) d \xi .
$$

Let us take $\Delta \omega_{2}^{*}=0$ in $(58)$.

From (57) and (1) one obtains

$$
W_{t d^{\prime}}(0, \eta)=\frac{\lambda_{t d^{\prime}}}{T_{r d^{\prime 2}}} \int_{-\infty}^{+\infty} f\left(x_{1},-\eta\right) d x_{1}
$$

In case of monoresonance

$$
I_{t d^{\prime}}^{0}=W_{t d^{\prime}}^{0}(0, \eta)=\frac{\pi \lambda_{t d^{\prime}}}{v_{1} T_{r d^{\prime 2}}}
$$

and hence

$$
\frac{I_{t d^{\prime}}(0)}{I_{t d^{\prime}}^{0}}=\int_{-\infty}^{+\infty} L_{t d^{\prime}}(-\eta) G(\eta) d \eta
$$

where

$$
L_{t d^{\prime}}(\eta)=\frac{v_{1}}{\pi} \int_{-\infty}^{+\infty} f\left(x_{1}, \eta\right) d x_{1}
$$

and equals to the left-hand side of $(61)$ in case of a homogeneous magnetic field. The integral (62) consists of two terms

$$
L_{t d^{\prime}}(\eta)=\left[1 \mp \tau_{1} S(\eta)\right] L_{t d^{\prime}}^{(1)}(\eta) \mp \frac{S(\eta)}{\tau_{2}} L_{t d^{\prime}}^{(2)}(\eta),
$$


where

$$
L_{i d^{\prime}}^{(1)}(\eta)=\frac{v_{1}}{\pi} \int_{-\infty}^{+\infty} f_{1}(Z, \eta) d Z
$$

and

$$
L_{t d^{\prime}}^{(2)}(\eta)=\frac{v_{1}}{\pi} \int_{-\infty}^{+\infty} f_{2}(Z, \eta) d Z
$$

The integral (64) exists and its value can be calculated as

$$
\int_{-\infty}^{+\infty} \frac{A_{1}(Z)}{B_{1}(Z)} d Z=2 \pi i \sum_{k}^{+} R_{k}^{(1)},
$$

where the residue $R_{k}^{(1)}$, corresponding to the root $Z_{k}$ of the polynomial $B_{1}(Z)$ is given by

$$
R_{k}^{(1)}=\frac{A_{1}\left(Z_{k}\right)}{B_{1}^{\prime}\left(Z_{k}\right)}
$$

$A_{1}(Z)$ is the nominator of $f_{1}(Z, \eta), B_{1}^{\prime}(Z)$ is the first derivative of the denominator. The sum in (66) is taken over residues $R_{k}^{(1)}$ corresponding to roots $Z_{k}$ with positive imaginary parts. The roots of $B_{1}(Z)$ are given by equations (16) and (17).

If $Z_{k}$ is a root of equation (10) then from (67) and (3) one obtains

$$
R_{k}^{(1)}=\frac{1}{2} \cdot \frac{1+Z_{k}^{2}}{p_{1}^{\prime}\left(Z_{k}\right)+i v_{1} q_{1}^{\prime}\left(Z_{k}\right)}
$$

Note that in our case $\bar{R}_{k}^{(1)}$ corresponds to the root $\bar{Z}_{k}$. It can be seen from (68) that $R_{3}^{(1)}=\bar{R}_{3}^{(1)}=0$. Using (16) and (17) we can calculate the values of $R_{1}^{(1)}$ and $R_{2}^{(1)}$, which yield

$$
R_{1}^{(1)}+R_{2}^{(1)}=-\frac{i}{2 v_{1}}
$$

The second integral (65) can be calculated by the same procedure. It should be remembered here that since $B_{2}(Z)=v_{1}^{2} D(Z)$ the roots $Z_{1}, Z_{2}$ of this denominator are also given by (16) and (17).

Thus

$$
R_{k}^{(2)}=\frac{1}{2} \cdot \frac{1 \pm i v_{2} \eta}{p_{2}^{\prime}\left(Z_{k}\right)+i q_{2}^{\prime}\left(Z_{k}\right)}
$$

Using the equations (4), (7), (8), (16) and (17) one obtains from (70)

$$
\begin{aligned}
& R_{1}^{2}=-\frac{i}{2 v_{1}} \cdot \frac{ \pm v_{2} \eta-i}{2 \alpha} \\
& R_{2}^{2}=+\frac{i}{2 v_{1}} \cdot \frac{ \pm v_{2} \eta-i}{2 \alpha}
\end{aligned}
$$


and from these equations

$$
R_{1}^{(2)}+R_{2}^{(2)}=0
$$

Hence, if $Z_{1}$ and $Z_{2}$ both have positive imaginary parts, we obtain from (66)

$$
\begin{gathered}
L_{t d^{\prime}}^{(1)}=1 \\
L_{t d^{\prime}}^{(2)}=0
\end{gathered}
$$

In this particular case, it follows from $(61),(63),(74)$ and (75) that

$$
\frac{I_{t d^{\prime}}(0)}{I_{t d^{\prime}}^{0}}=1 \mp \tau_{1} \int_{-\infty}^{+\infty} S(\xi) g(\xi) d \xi .
$$

In the derivation of (76) frequency units and symmetry properties of the spectral line have been used:

since

$$
L_{t d^{\prime}}(-\eta)=L_{t d^{\prime}}(\eta)
$$

$$
f\left(-x_{1},-x_{2}\right)=f\left(x_{1}, x_{2}\right) \text {. }
$$

It is noteworthy that the equation (76) is identical with (II 21) for intensities of spectral lines without a common energy level with the perturbed line. Since (II 21) is valid in both cases, whether there are common energy levels with the perturbed line or not, so are also the deductions therefrom, especially. (II 22) and (II 24), if only $Z_{1}$ and $Z_{2}$ both have positive imaginary parts.

It can be seen from (17) and (18) that (76) is valid in the special case $v_{1}=1$. This is rather a strict condition and probably only rarely fulfilled. But for the equation (76) to be valid it is sufficient to have

$$
\frac{v_{1}+1}{2 v_{1}}>\operatorname{Im} \alpha \text {. }
$$

For reasonably strong $r f$ fields $\gamma H_{2} \gg \frac{1}{T_{2}}$, where

the inequality

$$
h^{2} \gg\left(\frac{v_{1}-1}{2 v_{1}}\right)^{2}
$$

$$
h^{2}+\left(\frac{\eta}{2}\right)^{2} \gg|\eta| \cdot\left|\frac{v_{1}-1}{2 v_{1}}\right|,
$$

also holds independently of the value of $|\eta|$. Taking into account the inequalities (80) and (81) one obtains

$$
\operatorname{Im} \alpha \approx \frac{\left|\frac{\eta}{2}\right| \cdot\left|\frac{v_{1}-1}{2 v_{1}}\right|}{\sqrt{h^{2}+\left(\frac{\eta}{2}\right)^{2}}}
$$

and it can be seen that the inequality (79) holds in this case. Equation (76) and the equations (II 22) and (II 24) are therefore all valid for reasonably strong perturbing $r f$ fields even if there are line splittings. 


\section{Discussion}

A density-matrix analysis of the effects of a weak perturbing field $\mathrm{H}_{2}$ allowed a unified theoretical description of line splittings and intensity changes to be presented.

The rule of splittings for spectral lines with a common energy level $\left.{ }^{3}\right]$ as well as the dependence of line shape (in an inhomogeneous static magnetic field) upon the transition type $(\Lambda=0 ; 2)$ are confirmed. Positions of the halves of split lines depend upon relaxation parameters and only in the limit of stronger $r f$ fields $H_{2}$ approach the value given in [3]. In contrast to the theory presented by Freeman and Anderson, the line splitting begins at some $r f$ field strength that depends upon the relaxation parameters. At smaller $\mathrm{H}_{2}$ values the peak height of $\Lambda=0$ lines decreases, but for $\Lambda=2$ lires the peak height may either increase, go through a maximum and then diminish with splitting or simply decrease monotonously with increasing $r f$ field strength with splitting occurring at some appropriate value of $H_{2}$. The first type of $\Lambda=2$ lines and $\Lambda=0$ lines were investigated in several laboratories [4,5]. The exact shapes of split lines can be computed numerically and depend upon the relaxation parameters and inhomogeneity of the static magnetic field.

The line intensity changes caused by a perturbing rf field (nuclear Overhauser effect), can be described by a unified formula which is valid for a stronger $r f$ field for all lines, even in the case of line splittings.

The Bloch equations for the nuclear Overhauser effect ${ }^{6}{ }^{6}$ allow the use of line intensity measurements for relaxation coefficient determination. The first successful attempts have been made by Kuhlmann and Baldeschwieler [7]. This method of investigating relaxation phenomena offers considerable promise and the relationships for line intensities that are obtained in this series of papers allow it to be used on a fairly universal basis.

In particular, the possibility to use all lines, even the split lines, to measure the Overhauser effects and through them the relaxation coefficients, widens the possibilities of this sort of experiment considerably.

\section{Acknowledgements}

The authors wish to thank Maret Peterson and Vaige Salum for programming the line-shape computations. Acknowledgement is also due the Institute of Cybernetics Computing Center.

\section{REFERENCES}

1. Sinivee V., Lippma a E., Eesti NSV TA Toimetised, Füüs.-matem: ja tehn. tead. seeria, 14, 258 (1965).

2. Sinivee V., Lippma a E., Eesti NSV TA Toimetised, Füüs.-matem. ja tehn. tead. seeria, 14, 564 (1965).

3. Freeman R., Anderson W. A., J. Chem. Phys., 37, 2053 (1962).

4. Kuhl mann K. F., B aldeschwieler J. D., J. Am. Chem. Soc., 85, 1010 (1963).

5. K a is e r R. J., J. Chem Phys., 39, 2435 (1963).

6. B loch F., Phys. Rev., 102, 104 (1956).

7. Kuhlma nn K. F., B a ldeschwieler J. D., J. Chem. Phys., 43, 572 (1965). 
V. SINIVEE, E. LIPPMAA

\section{NORGA RAADIOSAGEDUSLIKU HÄIREVÄLJA EFEKTID TUUMA MAGNETILISES TOPELTRESONANTSIS. III}

Analüüsitakse varajasemas töös saadud valemit, mis kirjeldab ühiseid energianivoosid omavaid spektraaljooni. Spektraaljoone kuju muutumise käik häirevälja suurendamisel on erinev Freemani-Andersoni teoorias antust, sōltudes relaksatsiooni parameetritest. Valem spektraaljoone lōhenemise suuruse kohta langeb ühte Freemani-Andersoni valemiga ainult häirevälja suuremate tugevuste puhul. Spektraaljoone intensiivsuse valem on tugevamate häireväljade korral ühiseid energianivoosid omavatel joontel samasugune kui teistel joontel.

\section{B. СННИВЕЕ, Э. ЛИППМАА}

\section{ЭФФЕКТЫ СЛАБОГО ВОЗМУЩАЮЩЕГО РАДИОЧАСТОТНОГО ПОЛЯ В ЯДЕРНОМ МАГНИТНОМ ДВОЙНОМ РЕЗОНАНСЕ. III}

В работе подвергнута анализу полученная ранее формула, описывающая спектральные линии с общими уровнями энергии. Установлено, что ход изменения формы спектральной линии при увеличении возмущающего поля зависит от релаксационных параметров и отличается от хода, представленного теорией Фримана-Андерсона. Величина расщепления совпадает с формулой Фримана-Андерсона только при более сильных возмущающих полях. Показано, что формула для интенсивности спектральной линии с общим уровнем энергии в более сильных возмущающих полях совпадает с формулой, относящейся к другим уровням энергии. 